\title{
Museu como medium: reflexões sobre as interfaces entre comunicação e museologia
}

\author{
Lucimery Ribeiro ${ }^{1}$

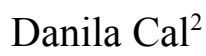

\begin{abstract}
Resumo: O objetivo deste trabalho é refletir sobre as interfaces entre Comunicação e Museologia. Propõe-se a ideia do museu como medium, considerando-o como ambiente de comunicação. De cunho teórico, o artigo parte das ponderações de literaturas dos campos da Comunicação e da Museologia a fim de compreender melhor os modos pelos quais a comunicação nos museus vem sendo abordada e reafirmar a postura democratizante dessa instituição perante a sociedade. Nesse cenário, os recursos tecnológicos destacam-se no processo de ressignificação das informações circuladas na sociedade. Conclui-se que, no desafio imposto pela conjugação de lazer e educação, as tecnologias de informação e comunicação contribuem para a disseminação, o conhecimento e ampliação do acesso aos acervos da instituição, permitindo a reconfiguração das relações entre museu e sociedade, além das potencialidades de preservação dos acervos e de interatividade com públicos distintos.
\end{abstract}

Palavras-chave: Ciberespaço. Comunicação. Museu. Sociedade.

Abstract: This work aims to reflect on the interfaces between Communication and Museology. It proposes the idea of the museum as medium, considering it as communicative environment. As a theoretical study, this article starts from the perspective of Communication and Museology fields literatures in order to better understand the ways by which the communication in museums has been addressed and reaffirm the democratizing posture of this institution to society. In that scenario, technological resources stand out in the process of resignification of the information circulated in society. It concludes that the challenge posed by leisure and education conjunction, information and communication technologies contribute to the dissemination, knowledge and access to the institution's acquis, allowing the reconfiguration of the relationship between museum and society, in addition to the preservation of collections capabilities and interaction with different audiences.

Keywords: Cyberspace. Communication. Museum. Society.

\section{Introdução}

No mundo globalizado em que vivemos, algumas instituições que, reiteradamente, enfrentam resistência para romper limitações impostas no decorrer do tempo, deixam de ser vistas como potencial comunicacional comunicativo junto à sociedade. $\mathrm{O}$ ritmo acelerado social e tecnológico faz com que apareçam novas formas comunicacionais a todo momento,

\footnotetext{
${ }^{1}$ Mestre em Comunicação, Cultura e Amazônia e bacharel em Museologia pela Universidade Federal do Pará (UFPA).

${ }^{2}$ Professora do Programa de Pós-Graduação em Comunicação, Cultura e Amazônia da UFPA e do Programa de Pós-Graduação em Comunicação, Linguagens e Cultura da Universidade da Amazônia - Unama. É doutora em Comunicação Social pela Universidade Federal de Minas Gerais - UFMG. É vice-líder do Grupo de Pesquisa Interações, Tecnologias e Amazônia (ITA-UFPA).
} 
sendo preciso estar atento às ambivalências na apropriação de cada ambiente comunicacional, tendo em vista que as ações e usos feitos em cada espaço refletem nas práticas sociais, ressignificando os hábitos e conceitos dos sujeitos envolvidos. Neste artigo, a partir de reflexões da interface entre as áreas de Comunicação e Museologia, tentaremos verificar o potencial dos museus como medium, a fim de refletir sobre os desafios e potencialidades dos seus processos comunicacionais estabelecidos no ciberespaço na contemporaneidade. Para isso, consideramos que:

\begin{abstract}
A função museológica é, fundamentalmente, um processo de comunicação que explica e orienta as atividades específicas do Museu, tais como a coleção, conservação e exibição do património cultural e natural. Isto significa que os museus não são somente fontes de informação ou instrumentos de educação, mas espaços e meios de comunicação que servem ao estabelecimento da interação da comunidade com o processo e com os produtos culturais (ICOM, 1992, p. 3).
\end{abstract}

O museu, como meio de comunicação, constitui-se por meio de "[...] sistemas de armazenamento, processamento e transmissão de mensagens culturais potencialmente interativas, dentro de, e para um determinado contexto social” (CASTELLS, 2011, p. 9), sendo capaz de ressignificar e reordenar práticas sociais já estabelecidas. Contudo, é necessário reconhecer e dominar as linguagens e recursos disponíveis, pois os mesmos podem permitir maior articulação entre as pessoas e os objetos que dão forma às narrativas expostas dentro dono tempo presente.

Uma possibilidade que permite o reconhecimento e legitimação do museu perante a sociedade, ao privilegiar a interação dos sujeitos envolvidos é, em geral, o uso do ciberespaço., Destacado por seu caráter dinâmico e flexível dentro do contexto de interligações que pode se configurar entre o local e o global. No ambiente do museu, as ações no ciberespaço podem auxiliar no rompimento de fronteiras de pensamentos e ações até então condicionadas pelo tempo, num espaço tendencialmente "arquivado" no passado. Todavia, antes de verificar melhor as potencialidades conferidas aos museus pelo ciberespaço, precisamos atentar ao conceito da instituição museológica, a fim de evitar eventuais mal entendidos sobre tais espaços, tendo em vista sua função e características. Seu principal conceito advém do Estatuto de Museus:

Art. $1^{\circ}$ Consideram-se museus, para os efeitos desta Lei, as instituições sem fins lucrativos que conservam, investigam, comunicam, interpretam e expõem, para fins 
de preservação, estudo, pesquisa, educação, contemplação e turismo, conjuntos e coleções de valor histórico, artístico, científico, técnico ou de qualquer outra natureza cultural, abertas ao público, a serviço da sociedade e de seu desenvolvimento (BRASIL, 2009, artigo $1^{\circ}$ ).

Partindo da delimitação conceitual e do entendimento do que vem a ser um museu, concentramos nossa atenção na comunicação estabelecida nas e pelas instituições, em especial a constituída no ciberespaço. Nesse contexto, é possível dar destaque à flexibilidade da troca de papéis entre os atores envolvidos, bem como às chances de acessibilidade e multiplicação da informação, deixando para trás a grande distância que se tinha no passado, pois como se pode notar:

\begin{abstract}
A internet expandiu as possibilidades de disseminação da informação das instituições museológicas para inúmeros usuários. Assim, os museus podem estar, pela primeira vez, libertos de seu localismo inerente e da fisicalidade que requer que seus usuários sejam 'visitantes em pessoa'. Os visitantes virtuais são os usuários dos museus por meio da Internet que podem ser também visitantes presenciais das instituições museológicas (CARVALHO, 2006, p. 128).
\end{abstract}

Os museus, ao estabelecerem estratégias diferenciadas para lidarem com pessoas e objetos, também ganham diferentes formas e características, o que pode servir como agente transformador no que concerne a algumas ideias pré-concebidas por parte da sociedade a respeito de tais instituições, aproximando-os mais e contribuindo para a disseminação, conhecimento e ampliação do acesso a suas coleções e acervo.

Com vistas a examinar tais desafios e potencialidades, nosso artigo se estrutura em três tópicos. O primeiro apresenta um comparativo entre os paradigmas informacional e relacional da Comunicação em relação às formas de comunicar das instituições museológicas. O segundo situa as instituições museológicas como um medium de comunicação, ao nos apropriarmos do conceito utilizado por Bastos (2012). E o terceiro tópico apresenta um breve panorama histórico e tipologias dos museus, a fim de destacar alguns dos desafios enfrentados na contemporaneidade. 


\title{
2. O Paradigma Informacional e Relacional da Comunicação e a Relação com a
} Museologia

Ao destacarmos que o artigo se dá na confluência entre as áreas de Comunicação e Museologia, de forma a evidenciar o caráter interdisciplinar de ambas as áreas, se faz faz-se necessário perceber a interface entre as formas de comunicar dos museus e os paradigmas comunicacionais: informacional ou epistemológico, e o relacional ou praxiológico, por meio de uma breve abordagem de cada modelo comunicacional e a relação estabelecida nos espaços museológicos.

Do ponto de vista comunicacional, o paradigma informacional orienta suas práticas para pensar apensa a comunicação num sistema linear, reduzindo-a em uma ordem de fenômeno mental que se encontra na cabeça de uma pessoa e passa para outra, num caráter pré-definido. Essta abordagem reforça um modelo de transmissão da informação, ao dar ênfase a uma relação de estímulo-resposta, onde o produtor é ativo e o receptor é passivo.

Partindo da conceituação de Ferreira (2010), compreendemos que:

\begin{abstract}
O modelo informacional ou a teoria da informação é, essencialmente, uma teoria da transmissão de signo, segundo o esquema proposto por Shannon. Assim, o signo coloca em relevo seu caráter portador de informação, acrescentando a condição de que ele tenha, deliberadamente, sido produzido por alguém e espera que ele será compreendido como tal na sua recepção [...]. De um lado, há uma fonte que emite signos no interior de um aparelho de transmissão e, de outro, existe um receptor que efetua a conversão desses signos para um destinatário. A mensagem, nesse aparelho, pode comportar ruídos (FERREIRA, 2010, p. 43).
\end{abstract}

Esse modelo comunicacional é conhecido como Teoria da Informação ou Teoria Matemática da Comunicação, e tem como base trabalhos de engenharia das telecomunicações. Destaca-se o estudo de Nyquist (1924), de Hartley (1928) e Shannon (1948). "Todos estes estudos têm por objectivo melhorar a velocidade de transmissão de mensagens, diminuir as suas distorções e aumentar o rendimento global do processo de transmissão de informação" (WOLF, 1995, p.100). Partindo do esquema proposto por Shannon - o Sistema Geral da Comunicação -, a transmissão otimizada é considerada como objetivo principal a transmissão otimizada das mensagens, cuja sistematização podemos conferir abaixo (FIGURA 1): 


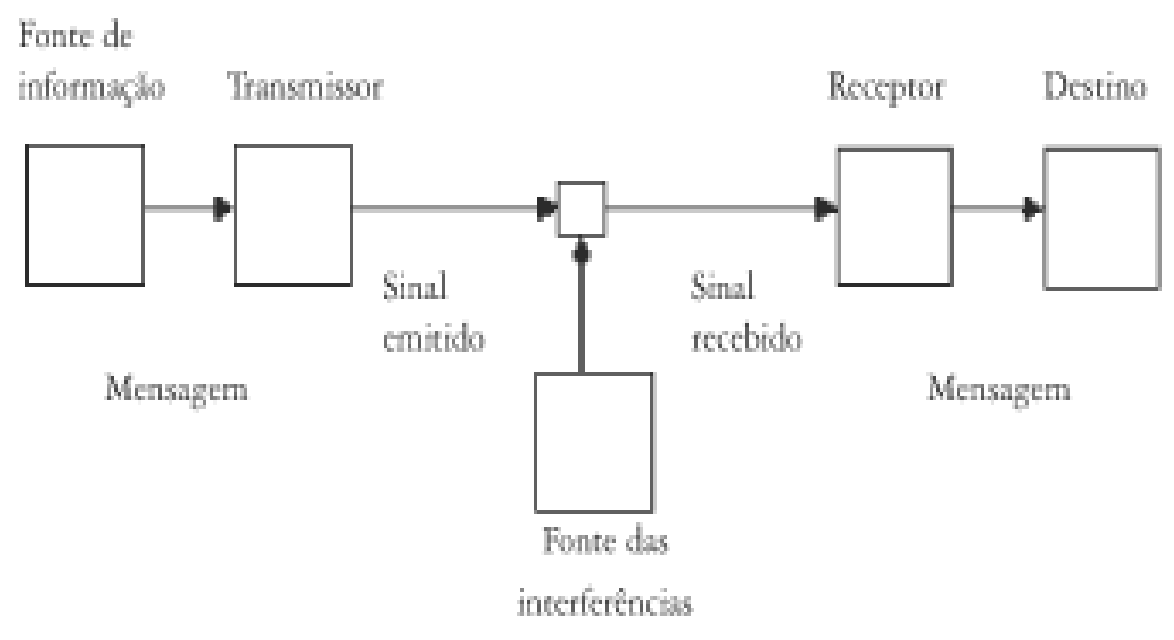

Fonte: CAPURRO; HJORLAND, $2007^{3}$.

Este esquema tem como finalidade estabelecer o modo mais econômico, rápido e seguro de codificar uma mensagem de um polo a outro, sem que as interferências no meio do processo comunicacional tornem-se problemas à transmissão. O que ganha destaque é o código, por possibilitar a transmissão da mensagem.

O código que interessa à teoria da informação - e que torna possível a transmissão de informação - serve para reduzir a equiprobabilidade inicial na fonte, estabelecendo um sistema de recorrências. É um sistema meramente sintáctico, um sistema organizador que não contempla, na sua pertinência própria, o problema do significado da mensagem, ou seja, a dimensão mais especificamente comunicativa (WOLF, 1995, p. 104).

O código se coloca como condição sine qua non para a existência da mensagem. "Embora 'todo o processo de comunicação entre seres humanos pressuponha um sistema de significação como condição necessária' [...]" (WOLF, 1995, p. 106), o significado da mensagem não tem importância neste modelo. Apesar disso, o mesmo foi bem recebido durante muito tempo e aplicado em fenômenos heterogêneos de processo comunicacional, como poderá ser visto na aplicação aos museus.

Em estudo de Adriana Mortara Almeida e Maria Margaret Lopes, que versa sobre os modelos de comunicação e suas aplicações em museus, encontramos uma adaptação do

${ }^{3}$ Disponível em: <http://www.scielo.br/img/revistas/delta/v19n1/18994f5.gif>. 
modelo de Shannon ao ambiente do museu. Essta adequação foi formulada por uma pesquisadora britânica, chamada Eilean Hooper-Greenhill, e mostra como cada elemento da comunicação nos museus se encaixaria no esquema de Shannon (FIGURA 2).

FIGURA 2 - Sistema Geral da Comunicação de Shannon aplicado aos museus

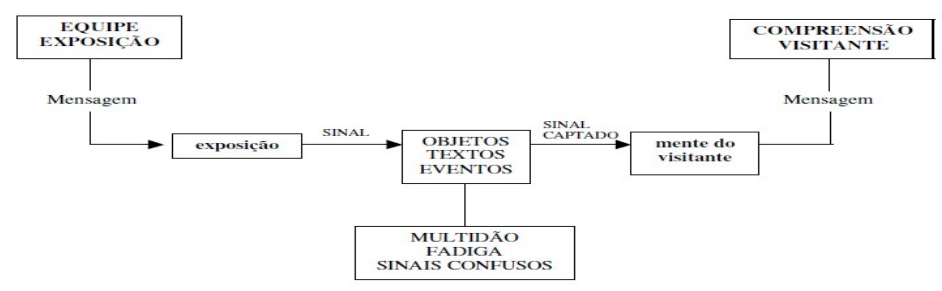

Fonte: ALMEIDA; LOPES, $2003^{4}$.

É possível notar que as experiências do visitante são desconsideradas e apenas as vivências do produtor são levadas em consideração, de tal modo que o visitante não pode contestar o que foi recebido. Esse funcionamento faz com que se estabeleça um distanciamento dos museus em relação aos variados segmentos sociais, haja vista que a narrativa exposta foi elaborada por um número pequeno de indivíduos cuja intenção é pessoal, baseada em seu próprio modo de ver e entender o mundo. Isso acarreta em sistemas de pensamentos fechados, caracterizando o museu como autocrático e contemplativo.

Considerando que o museu se constitui sob a tríade homem $\mathrm{x}$ objeto $\mathrm{x}$ cenário, outros códigos de comunicação, como as linguagens, as vivências e culturas de cada participante do processo vêm à tona para remodelar as formas pelas quais a instituição museológica se aproxima do público. E o novo modelo de comunicar, caracterizado pela interação produzida entre os agentes envolvidos no processo de comunicação, cada vez mais valorizado nos estudos de comunicação, ganha força nas instituições museológicas e remodela suas ações internas e externas.

Tendo em vista o processo de alargamento no domínio dos estudos da comunicação e a preocupação com o rendimento do fluxo informacional, a atenção desloca-se, paulatinamente, para a produção de sentido.

${ }^{4}$ Disponível em: <http://www.unitau.com.br/scripts/prppg/humanas/download/modelcomunicapli-v9-n2-03.pdf>. 


\begin{abstract}
A comunicação é, pois, tomada em seu aspecto experiencial: nela fundamentam-se pontes de interação entre sujeitos e/ou objetos de tal modo que os envolvidos afetam-se, numa espécie de 'comunhão' através da qual os sentidos vão sendo estabelecidos. Esse processo, para além da simples emissão e recepção de mensagens, funciona como constituidor dos sujeitos e da realidade social na medida em que instaura um mundo comum e intersubjetivamente partilhado (SANTOS; DIONÍZIO, 2010, p. 6).
\end{abstract}

Tais características pautam o paradigma relacional da comunicação, que pensa suas ações além da linguagem entre um e outro sujeito e reflete também sobre a situação em que se dá a comunicação, ao levar em consideração as configurações do lugar que intervém, conferindo-a um caráter encarnado (FRANÇA, 2003; QUÉRÉ, 1991).

Partindo para a comparação ao campo museológico, tal colocação nos museus foca nas negociações de sentidos e experiências proporcionadas pelos sujeitos envolvidos na narrativa do espaço. O museu pautado no monólogo dá lugar ao diálogo, onde as ações e atividades são (re)pensadas, a partir das experiências individuais e coletivas dos agentes envolvidos. De acordo com Cury (2005):

\footnotetext{
Certamente esta postura mexe muito com as ideias também hegemônicas dos museus como meio de comunicação. Mexe, ainda, com a visão dos lugares, ou posições, do museu, e seu pessoal, como emissores e do público como receptores [...]. Certamente o museu terá que repensar as suas posições e formas de atuação. E certamente, a partir dessa concepção, o público será visto como ator, como ativo, e não como consumidor passivo, o cliente (CURY, 2005, p. 41-42).
}

Ao remodelar seus esses pré-conceitos, como a limitação de codificador para o emissor e decodificador para receptor, os museus passam a atuar na construção e negociação de significados, deslocando o caráter informacional do processo de comunicação para o relacional. Assim, a comunicação nos museus passa a integrar produção e reconhecimento, não se restringindo apenas a apreensão de códigos puros e simples, e dá destaque ao significado das trocas estabelecidas no processo comunicacional.

\title{
3. Museu como Medium
}

Ao considerarmos que os processos ocorridos nos museus permitem a apreensão transformada dos sentidos dos objetos em outros tempos e espaços, por seu potencial informativo e pela condição em sistematizar as formas de assimilação do conhecimento e de 
(re)criação de diversas memórias na atualidade, entendemos o museu como meio de comunicação.

O conceito de meio - medium - do qual nos apropriamos advém da definição consensual dos estudos alemães e pode ser compreendido como qualquer espaço vazio e intermediário que, ao ser preenchido, permite a articulação entre os significados propostos por suas mensagens e a incorporação de tais no cotidiano dos atores envolvidos, dando forma a tudo o que foi circulado (BASTOS, 2012). Segundo Bastos:

\begin{abstract}
O conceito de medium na tradição alemã é, contudo, um desenvolvimento da acepção seminal oferecida por Aristóteles (1978). [...] Para Aristóteles há sempre um atributo sensível que causa um movimento no medium (ar, água ou terra), que por sua vez produz movimento nos órgãos do sentido. [...]. Mas a acepção comunicacional do conceito de medium só começou a tomar forma a partir da obra do austríaco Fritz Heider, cujo pensamento foi influenciado pelo corpus aristotelicum. Para Heider (1921), um medium compreende uma massa de elementos reunidos de modo disperso e transigente, sem nenhuma configuração fixa, mas que adquirem uma forma rígida tão logo alguma força se aplique sobre o medium [...] (BASTOS, 2012, p. 56).
\end{abstract}

Podemos dizer que os museus se caracterizam como o medium que possibilita várias percepções espaço-temporais pela pluralidade de relações que se estabelecem pelo mesmo e por seus recursos, permitindo interação em ambiente presencial ou virtual. Um exemplo são as exposições compostas por objetos que permitem o toque e dão ênfase não há um roteiro definido, mas a interação entre visitante e acervo, fazendo com que a compreensão da narrativa exposta só seja possível com a participação completa do público, através de todos os seus sentidos.

As trocas que podem se configurar na interlocução entre produtor e visitante possibilitam, a partir de conexões afetivas e/ou identitárias, que o museu seja evidenciado ou não na sociedade, haja vista que a ausência de pertencimento às narrativas expostas pelo museu impedem que a sociedade estabeleça laços efetivos que culminem na troca de conhecimentos e valores. Para fortalecimento dessa relação, o museu precisa atualizar-se mediante as necessidades do tempo presente, construindo estratégias narrativas que integrem o passado e presente, sempre buscando apresentar os fatos a partir de uma ótica plural que permita o máximo possível de interpretações. 
Esta é a grande riqueza que o museu pode proporcionar à sociedade: constituir-se como instância de autoconhecimento e de (re)conhecimento do Outro - movimentos fundamentais na constituição de uma relação digna do indivíduo consigo mesmo e com o mundo [...] (SCHEINER, 2003, p. 5-6).

O museu é, portanto, uma instituição social com alto potencial de construção sígnica, constituído a partir de percepções identitárias, expressando-se sob as mais diferentes formas no tempo e no espaço. Todavia, é preciso estar atento ao caráter relacional que se constitui nas instituições museológicas, tendo em vista o equilíbrio entre as possibilidades de interpretação do outro e as narrativas construídas a partir de lembranças e silenciamentos do produtor que podem conduzir as tendências de observação do visitante.

Ao considerarmos a importância da apropriação de novos recursos e ferramentas de comunicação para dentro dos museus, enquanto exigências da transformação tecnológica e principalmente cultural, focamos na capacidade do ciberespaço. Além de inter-relacionar coisas e pessoas em todas as partes do mundo, democratiza o acesso de variados segmentos sociais ao conteúdo produzido pelo museu através de outra dimensão espaço-temporal que se dá na internet, um recurso auxiliar para legitimidade do museu perante a sociedade.

A Internet é “[...] um meio de comunicação, de interação e de organização social" (CASTELLS, 2003, p. 255), e o seu uso contribui para a constituição de um mundo mais perceptível às suas diferenças e necessidades. Quando apropriada pelas instituições museológicas, é capaz de dar destaque à representação da memória cultural no contexto das plataformas digitais, a partir dos recursos tecnológicos que sugerem a transposição de limites tradicionais ligados à experiência e à rememoração, resultando no auxílio da constituição dos conceitos de cidadania e identidade.

Ao apropriar-se dessas multiplicidades de relações/conexões, algumas instituições museológicas podem se configurar totalmente no ciberespaço - sendo chamadas de museu virtual, integrando o conceito de interatividade no percurso museológico e possibilitando várias alternativas de fruição ao usuário -, e outras de maneira parcial - apresentando um caráter híbrido, onde a tipologia que se ressalta é sempre a da instituição física, usando os ambientes virtuais apenas para difundir informações sobre o conteúdo do seu acervo e das atividades culturais desenvolvidas no seu espaço físico. 


\section{Breve Histórico e Tipologias de Museus}

Ao evidenciarmos o potencial dos museus, a partir da perspectiva relacional da comunicação, na busca em adaptar-se às demandas sociais e agenciar trocas culturais que ressignifiquem conceitos pré-determinados pelo tempo e espaço, verificamos um considerável aumento do número de museus nas mais diversas tipologias, que vão desde os museus tradicionais até ecomuseus, entre outros. Para melhor compreensão da heterogeneidade dos museus e seus modos de atuação, traçamos um breve histórico a respeito da constituição de tais instituições na sociedade.

A palavra museu vem de mouseion - do latim museum - e, de acordo com a mitologia grega, era o templo das musas, as nove filhas de Zeus - rei dos deuses - e Mnemósine - a deusa da memória -, que possuíam a capacidade de inspirar a criação artística e científica. Elas são: Calíope, representando a poesia épica; Clio, a história; Erato, a poesia lírica; Euterpe, a música; Melpômene, a tragédia; Polímnia, a música sacra; Tália, a comédia; Terpsícore, a dança; e Urâna, a astronomia. Seus poderes fundem todos os tempos: passado, presente e futuro; e sua moradia é a referência mais antiga de local de preservação cultural.

Indo além da designação de um espaço que remetesse ao início da história dos museus, há indícios históricos que pontuam geograficamente um local na Grécia que assumia características similares de representação: um templo na colina de Hélicos, em Atenas. Reunindo sábios da Filosofia e das Artes para construir saber sob a inspiração e proteção das musas, ao remeter-se ao caráter mitológico das entidades ligado à inspiração. Isso assinala o que seria considerado, séculos depois, o espaço físico dos museus e sua associação a um ambiente sagrado, em virtude da presença inspiradora das musas.

Enquanto criação euro-ocidental, a origem das instituições museológicas foi constituída "[...] por categorias classificatórias, ordenadas do mundo [...] onde surgiram as primeiras iniciativas de proteção dos objetos evocativos da história nacional e foram consolidados os mitos fundadores e a história oficial" (SALADINO, 2008, p. 48).

Segundo Dias (2001), entre os séculos XVI e XVIII, os objetos das colônias africanas e de outros locais fora das metrópoles europeias, incluindo as das Américas, foram considerados como "maravilhas" e, por conta disto, expostos nos Gabinetes de Curiosidades (FIGURA 3). Esses espaços se constituíam em espaços reservados ao deleite de 
colecionadores de obras de artes e peças raras, sem a intenção de permitir a troca de sentidos e a construção de significados possíveis na interação com variadas pessoas. Segundo Marandino, [...] eram coleções misturadas de curiosidades, artes e objetos culturais e naturais que, paulatinamente, foram se transformando e se especializando, traduzindo uma organização baseada na nascente delimitação das áreas de pesquisa e conhecimentos [...] (MARANDINO, 2008, p. 8).

FIGURA 3 - Gabinete de Curiosidade

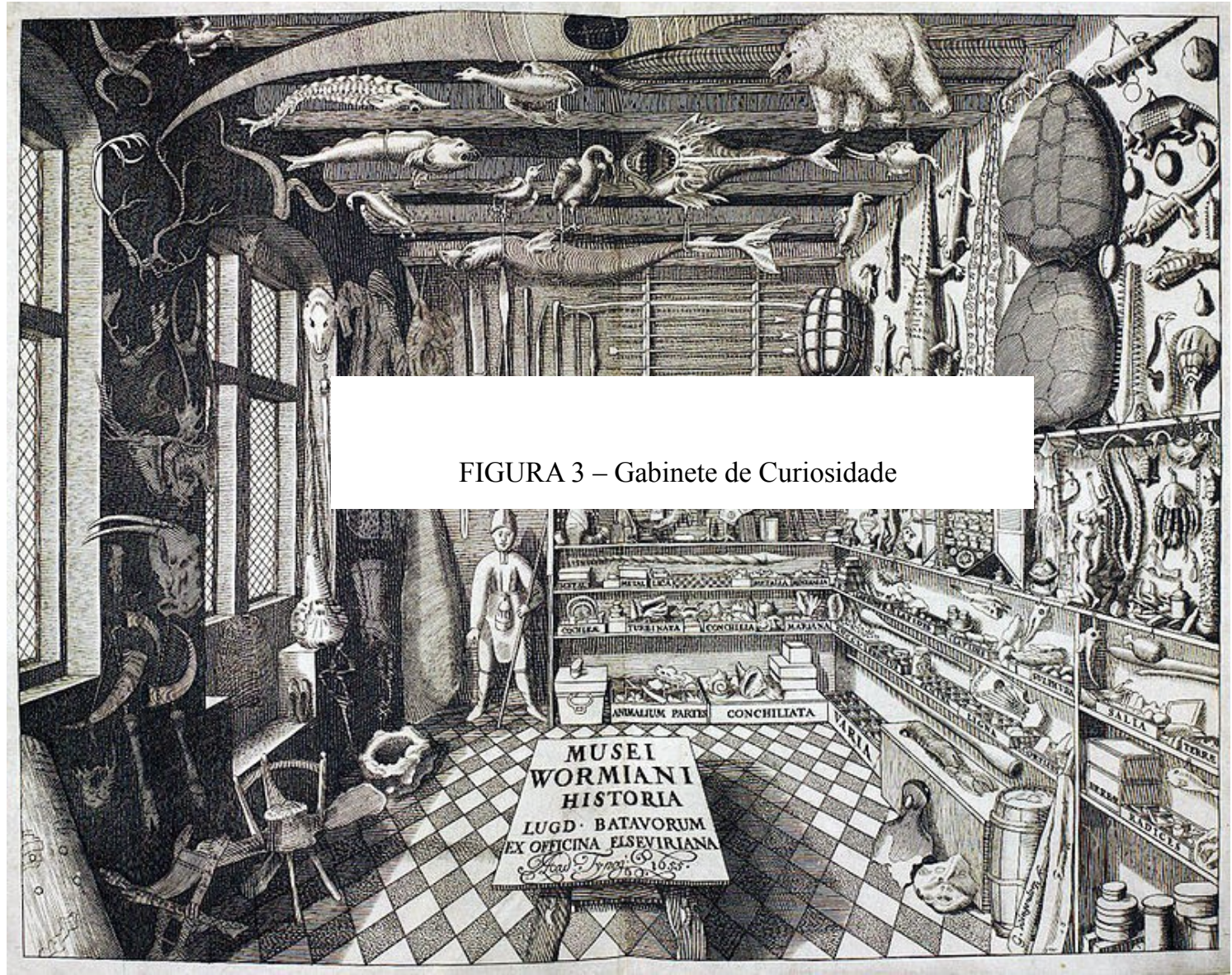

Fonte: Site Oficial da Universidade de Copenhague

Esses espaços representam o ápice de uma tradição colecionista e traduzem uma preocupação com a memória, onde suas coleções tornam-se referenciais de poder e destaque social. Ainda no século XVIII, surgiram os Museus Nacionais, com a constituição do Estado-

${ }^{5}$ Disponível em: <http://universitetshistorie.ku.dk/leksikon/m/museum_wormianum/>. 
Nação ${ }^{6}$. O protótipo inicial do que vem a ser museu na atualidade passa a ter um caráter comemorativo, a partir da criação de um sentimento de identidade nacional nas pessoas. Nesses espaços rememoravam-se vitórias e expunham bens obtidos nas conquistas em guerras. Evidenciam-se, desta maneira, mudanças nas formas de expor, consequentemente, no contato entre sociedade e museu. De acordo com Marandino:

A partir desse momento, os museus passaram a desempenhar um papel mais relevante na sociedade, em estreita colaboração com os governos nacionais de cada país. O século XIX, chamado de "século de ouro" dos museus, testemunha o crescimento e a ampliação dessas instituições em todo o mundo (MARANDINO, 2008, p. 8).

Assim, houve um grande aumento no número de museus fora do eixo central na Europa, seguindo a tendência inaugurada pelos museus coloniais que não se contentava apenas em constituir coleções com base nas riquezas nacionais, mas procurava mostrar o seu poder, ao deter os bens provenientes de outras regiões como parte de sua história. Isso ajudava a estabelecer uma cronologia histórica linear e evolutiva de um passado mítico até o tempo presente de cada país.

No século XX, os museus começam a passar por uma transformação em seus modelos, influenciados por movimentos surgidos no campo museológico da Europa do Leste e América Latina, devido às demandas sociopolíticas da época, suscitando questionamentos acerca do papel e função social do museu. Nesse processo de transformação é visível a substituição da perspectiva informacional para a relacional, no que concerne ao modo de relação estabelecido com a sociedade.

Durante as décadas de 60 e 70 se processou o alargamento da noção de determinados termos no campo da Museologia, o conceito clássico de museu - que operava com as noções de edifício, coleção e público - foi confrontado com novos conceitos, novas abordagens, que ampliavam e problematizavam o que era antes, de certa forma, estigmatizado socialmente (SOTO, 2014, p. 67-68).

\footnotetext{
${ }^{6}$ Durante quase toda a Idade Média, não existiam países como os que conhecemos hoje. As pessoas sentiam-se ligadas a uma cidade ou feudo. Somente no final do século XII, que o processo de formação das nações se iniciou, criando leis nacionais, línguas nacionais e etc., trazendo implantação e/ou ampliação de novos conceitos e modificação no modo de vida da sociedade. Um dos conceitos alargados com o surgimento dos estados nacionais foi o de patrimônio. "[...] Em tais sociedades, ele não era algo público e compartilhado, mas privado e aristocrático, fora de coleções de antiguidades, como no famoso caso do imenso acervo dos papas que, hoje, está no museu do Vaticano. O surgimento dos Estados Nacionais era o que faltava para desencadear uma transformação radical no conceito de patrimônio" (FUNARI, 2006, p. 15).
} 
Fatos históricos como a elaboração da Carta de Santiago do Chile (1972), a criação do Comitê Internacional de Museologia (ICOFOM - 1977) dentro do Conselho Internacional de Museus (ICOM - 1946) e o Movimento Internacional da Nova Museologia (MINOM) foram primordiais para estabelecer novos paradigmas e pressupostos teóricos no campo da Museologia, especialmente na América Latina, onde essas transformações tiveram mais ecos, consolidando, assim, novos modelos de museus.

A partir deste breve contexto histórico, consideramos que os museus são instituições heterogêneas, tendo evoluído dos clássicos museus de acervo para museus produtores de narrativas, compreensão e produção de conhecimentos sobre temas variados, que envolvem questões históricas, artísticas, sociológicas, econômicas e políticas. Assim, apresentam-se em diferentes potenciais e dinâmicas de organização perante a sociedade, a partir dos desafios impostos na contemporaneidade, com potencial comunicacional junto à sociedade.

\section{Considerações finais}

Além da transformação do papel dos museus e da multiplicidade de tipologias que surgem na tentativa de estabelecer uma gestão participativa e compartilhada com os variados segmentos sociais, verificamos que a apropriação de recursos comunicacionais também permitiu a expansão de acesso às informações que as instituições museológicas obtêm e a construção de laços sociais não delimitados pelo tempo e espaço.

Atualmente, os que mais se destacam no processo de ressignificação das informações circuladas na sociedade são os recursos tecnológicos. Capazes de interligar diferentes formas de expressão cultural numa compreensão de tempo/espaço menor, tendo em vista os espaços de fluxos, antes delimitados por fronteiras não flexíveis, faz com que agora, se dissipem as delimitações e ampliem os horizontes. "A tecnologia, que foi durante a modernidade um instrumento de racionalização e de separação, parece transformar-se numa ferramenta convivial e comunitária” (LEMOS, 2013, p. 82).

As consequências dessas tecnologias para a comunicação e a cultura são remarcáveis [...]. O aspecto mais espetacular da era digital está no poder dos dígitos para tratar toda informação, som, imagem, vídeo, texto, programas informáticos, com a mesma linguagem universal, uma espécie de esperanto das máquinas. Graças à digitalização e compressão dos dados, todo e qualquer tipo de signo pode ser 
recebido, estocado, tratado e difundido, via computador. Aliada à telecomunicação, a informática permite que esses dados cruzem oceanos, continentes, hemisférios, conectando potencialmente qualquer humano no globo, numa mesma rede gigantesca de transmissão e acesso que vem sendo chamada de ciberespaço (SANTAELLA, 2003, p. 71).

Entendemos ciberespaço, portanto, como um espaço interconectado por recursos tecnológicos em rede e, quando conectado à Internet, permite a troca de dados de maneira fluida (MARTINO, 2014). Isso traz aspectos importantes para as relações sociais, como a reorganização de limitações impostas por distância e espaço, proporcionando maior liberdade aos sujeitos envolvidos nas relações.

Com a expansão do uso dos recursos tecnológicos em vários setores da sociedade, os museus de todas as tipologias também visualizam o alargamento de sua dinâmica de produção, circulação e difusão das informações, de modo que seu uso não fique restrito apenas à veiculação das palavras, mas que possibilite processos de reflexões individuais e coletivas pelas conexões estabelecidas entre museu e sociedade.

Lança-se aos museus o desafio de adequar às linguagens e métodos disponíveis as demandas sociais, haja vista que a atenção, antes voltada para o objeto em exposição no processo informacional de comunicação dos museus, volta-se aos atores envolvidos sob a ótica do paradigma relacional da comunicação. O modelo de museu da atualidade pauta-se nas múltiplas e complexas relações que cada pessoa estabelece com o mundo real, sendo assim, deve instrumentalizar os recursos disponíveis ao seu uso, de modo a equacionar aos seus objetivos e a valorização das experiências permitidas em seu espaço, enquanto ponto de encontro e produtor de noções identitárias.

Destacamos que dentro desse processo de apropriação dos ambientes disponíveis no ciberespaço, os museus precisam atentar para a lógica de uso das tecnologias de informação e comunicação, caso contrário, a apropriação apenas em decorrência das exigências tecnológicas acaba por classificar as atividades do museu sem fins educativos e sociais, visando apenas à atração indiscriminada de visitantes, efetivos e em potencial, sem a preocupação com a transformação da informação em conhecimento.

Os museus, em termos de mercado, competem com um grande número de empreendimentos da indústria cultural e do entretenimento que contam com marketing agressivo: parques temáticos, cinemas interativos e casas de jogos eletrônicos, entre outros. Todavia, o trabalho dos museus não se confunde com o 
dessas indústrias, pois as instituições museológicas trabalham principalmente em uma dimensão educacional que visa ao desenvolvimento cultural e social dos cidadãos. É inegável que existe uma demanda social por programas educativoculturais e, nesse sentido, os museus e outras instituições afins podem contribuir significativamente para atendê-la. Essa demanda se insere também em um contexto de lazer e entretenimento. O grande desafio do museu está em conjugar educação e lazer [...] (STUDART, 2010, p. 141).

No desafio imposto pela conjugação de lazer e educação, as tecnologias de informação e comunicação contribuem para a disseminação, o conhecimento e ampliação do acesso aos acervos da instituição, permitindo a reconfiguração das relações entre museus e sociedade, além das potencialidades em de preservação dos acervos e da interatividade com públicos distintos.

\begin{abstract}
A interação homem-tecnologia tem evoluído a cada ano no sentido de uma relação mais ágil e confortável. Vivemos hoje a época da comunicação planetária fortemente marcada por uma interação com as informações, cujo ápice é a realidade virtual. A interatividade digital caminha para a superação das barreiras físicas entre os agentes (homens e máquinas) e para uma interação cada vez maior do usuário com as informações, e não com os objetos (LEMOS, 2013, p. 113).
\end{abstract}

A partir dessas novas relações sociais, os discursos, até então restritos às trocas em determinada realidade regional, ganham possibilidades de visibilidade com proporções globais, devido à diluição das fronteiras ocasionadas pelo advento da internet. As dissoluções ocorridas permitem que novos vínculos sociais e afetivos sejam estabelecidos, desde a assimilação de um novo conceito de tempo e espaço, introduzido pela globalização, e a fluidez das informações na dinâmica atual.

Sendo assim, refletir sobre o museu como medium frente aos outros espaços comunicacionais, aponta a abertura de novos olhares para o amplo potencial de tais instituições junto à sociedade, além da compreensão quanto à necessidade de ampliação de trabalhos que versem Comunicação e Museologia, a fim de permitir um alargamento das perspectivas das áreas em questão. Do ponto de vista comunicacional, o artigo contribui também para pensar a própria Comunicação, tendo em vista uma abordagem ampla dos fenômenos que não se restringem aos midiáticos. Do ponto de vista museológico, considerase a capacidade de aprimoramento das ações comunicacionais estabelecidas pelo e no museu, de modo que não se reduza o seu potencial comunicacional, seja no espaço físico e/ou virtual. 


\section{Referências}

ALMEIDA, A. M.; LOPES, M. M. Modelos de comunicação aplicados aos estudos de públicos de museus. Revista de Ciências Humanas (Taubaté), Taubaté, v. 9, n.2, p. 137-145, 2003.

Disponível

em

http://www.unitau.com.br/scripts/prppg/humanas/download/modelcomunicapli-v9-n2-03.pdf acesso em 05 mar. 2016

BASTOS, Marco Toledo. Medium, media, mediação e midiatização - a perspectiva germâmica. In: Mediação \& Midiatização / Jeder Janotti Junior, Maria Ângela Mattos, Nilda Jacks, Organizadores; prefácio, Adriano Duarte Rodrigues. - Salvador: EDUFBA; Brasília: Compós, 2012. 327 p. / Livro Compós 2012.

BRASIL, Lei no 11.904, de 14 de Janeiro de 2009. Institui o Estatuto de Museus. Disponível em: <http://www.planalto.gov.br/ccivil_03/_Ato2007-2010/2009/Lei/L11904.htm>. Acesso em 22 jun. 2014.

CABRAL, Magaly. O educador de museu frente aos desafios econômicos e sociais da atualidade. In: $\mathrm{O}$ ICOM/Brasil e o pensamento museológico brasileiro: documentos selecionados / organização Maria Cristina Oliveira Bruno. - São Paulo: Pinacoteca do Estado: Secretaria de Estado da Cultura: Comitê Brasileiro do Conselho Internacional de Museus, 2010.

CAPURRO, Rafael; HJORLAND, Birger. The concept of information as we use in everyday. Perspectivas em ciência da informação, v. 12, n. 1, p. 148-207, 2007.

CARVALHO, Rosane Maria Rocha de. As transformações da relação museu e público sob a influência das tecnologias da informação. In: MUSAS - Revista Brasileira de Museus e Museologia, n. 2, 2006. Rio de Janeiro: Instituto do Patrimônio Histórico e Artístico Nacional, Departamento de Museus e Centros Culturais.

CASTELlS, Manuel. Internet e Sociedade em Rede. In: MORAES, Dênis de (Org.). Por Uma Outra Comunicação: Mídia, mundialização cultural e poder. Rio de Janeiro: RECORD, 2003.

Museus na era da informação: conectores culturais de tempo e espaço. In: MUSAS Revista Brasileira de Museus e Museologia, n.5, 2011. Brasília: Instituto Brasileiro de Museus, 2011.

CURY, Marília Xavier. Exposição: concepção, montagem e avaliação. São Paulo: Annablume, 2005.

DIAS, José António B. Fernandes. Arte e antropologia no século XX: modos de relação. In: Etnográfica, Vol. V (1), 2001, pp. 103-129. Disponível em: 
$<$ http://ceas.iscte.pt/etnografica/docs/vol_05/N1/Vol_v_N1_103-130.pdf $>$. Acesso em: 14 jan. 2016.

FERREIRA, Giovandro Marcus. Teorias da Comunicação, Teorias do Discurso: Em Busca do sentido. In: Teorias da comunicação: trajetórias investigativas / Giovandro Marcus Ferreira, Antonio Hohlfeldt, Luiz C. Martino, Osvando J. de Morais, organizadores - Porto Alegre: EdiPUCRS, 2010.

FRANÇA, V. V. L. Quéré: dos modelos da comunicação. In: Revista Fronteiras. Estudos Midiáticos. Vol. V, nº 2. São Leopoldo: Unisinos, 2003.

FUNARI, Pedro Paulo Abreu. Patrimonio Histórico e Cultural / Pedro Paulo Funari e Sandra de Cássia Araújp Pelegrini. - Rio de Janeiro: Jorge Zahar Ed., 2006.

GUARESCHI, Pedrinho; GALANTE, Claudia. Convergência midiática: uma nova forma de participação democrática. Anais. XV ENABRAPSO, 2009. Disponível em: $<$ http://abrapso.org.br/siteprincipal/images/Anais_XVENABRAPSO/369.\%20converg \%CAncia\%20midiatica.pdf $>$. Acesso em: 09 jun. 2015.

ICOM - Comitê venezuelano do Conselho Internacional de Museus. Declaração de Caracas, 1992. Disponível em: $<\mathrm{http}$ //www.revistamuseu.com.br/legislacao/museologia/decl_caracas.asp $>$. Acesso em: 24 abr. 2015 .

LEMOS, André. Cibercultura: tecnologia e vida social na cultura contemporânea / André Lemos. - 6. ed. - Porto Alegre: Sulina, 2013.

LOURENÇO, Maria Cecília França. Museus acolhem Moderno. São Paulo. Editora da Universidade de São Paulo, 1999.

MARANDINO, Martha. Educação em Museus: a mediação em foco - Universidade de São Paulo/ Faculdade de Educação, São Paulo - 2008.

MARTINO, Luís Mauro Sá. Teoria das Mídias Digitais: linguagens, ambientes, redes / Luís Mauro Sá Martino. - Petrópolis, RJ: Vozes, 2014.

QUÉRÉ, L. D'um modele épistemologique de la communication à um modele praxéologique. In: RÉSEAUX no 46/47. Paris: Tekhné, mar-abr 1991.

SALADINO, Alejandra. Museus da Ibero-América: para uma mudança de paradigmas. In: Revista Eletrônica Jovem Museologia, Rio de Janeiro, V. 3, N. 5, pp. 48-59, 2008. Disponível em: $<$ http://www.unirio.br/jovemmuseologia/documentos/5/alejandrasaladino_artigo.pdf $>$. Acesso em: 28 jun. 2014. 
SANTAELlA, Lucia. Culturas e Artes do Pós-Humano: da cultura das mídias à cibercultura / Lucia Santaella; [coordenação Valdir José de Castro]. - São Paulo: Paulus, 2003.

SANTOS, Ana Carolina Lima; DIONÍZIO, Priscila Martins. Sobre uma abordagem propriamente comunicacional: experiência, prática e interação. Disponível em: http://www.intercom.org.br/papers/nacionais/2010/resumos/r5-1867-2.pdf Acesso em 04 fev. 2016.

SCHEINER, Tereza. Comunicação, Educação, Exposição: novos saberes, novos sentidos. In: Semiosfera - Revista de Comunicação e Cultura, Rio de Janeiro, ano 3, N. 4-5, 2003. Disponível em: $<$ http://www.semiosfera.eco.ufrj.br/anteriores/semiosfera45/conteudo_rep_tscheiner.htm $>$. Acesso em: 16 out. 2014.

SOTO, Moana Campos. Dos gabinetes de curiosidade aos museus comunitários: a construção de uma concepção museal à serviço da transformação social. In: Cadernos de Sociomuseologia $\mathrm{N}^{\mathrm{0}} 4-2014$, vol 48, pp. 57-81. Disponível em: $<$ http://revistas.ulusofona.pt/index.php/cadernosociomuseologia/article/view/4987/3298>. Acesso em: 06 mai. 2015.

SCHWARCZ, Lilia. O espetáculo das raças, instituições e questão racial no Brasil - 18701930. São Paulo: Companhia das Letras, 1993.

STUDART, Denise C. Conceitos que transformam o museu, suas ações e relações. In: $\mathbf{O}$ ICOM/Brasil e o pensamento museológico brasileiro: documentos selecionados / organização Maria Cristina Oliveira Bruno. - São Paulo: Pinacoteca do Estado: Secretaria de Estado da Cultura: Comitê Brasileiro do Conselho Internacional de Museus, 2010.

WOLF, Mauro. Teorias da Comunicação. 4ª Edição, Lisboa, Editorial Presença, 1995. 